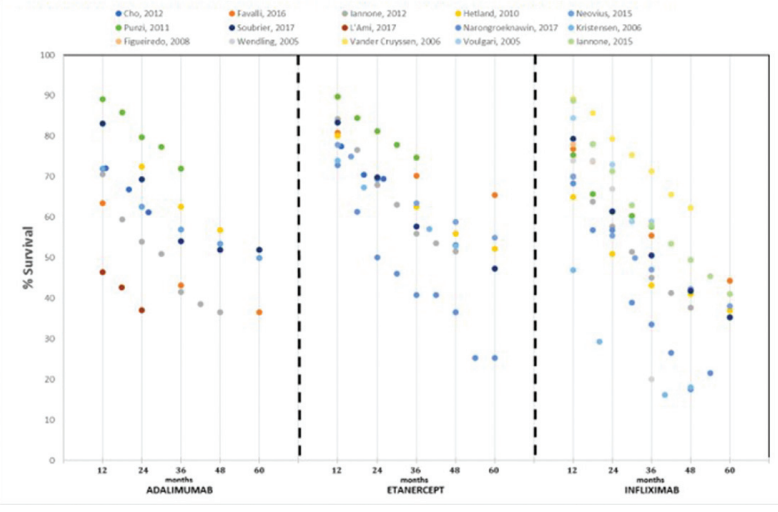

Abstract AB0460 - Figure 1. Survival of First-Line Anti-TNF Therapies in Patients with Rheumatoid Arthritis

Conclusions: Long-term survival rates for ADA, ETN, and IFX were similar and relatively high for treatment periods up to 36 months. After 36 months, there was a noticeable decline in drug survival for all three TNF $\alpha$ inhibitors. Heterogeneity in study size and design may contribute to the range of survival data for each agent.

Disclosure of Interest: P. Emery Consultant for: Pfizer, MSD, Abbvie, BMS, UCB, Roche, Novartis, Samsung, Sandoz and Lilly, B. Vlahos Shareholder of: Pfizer, Employee of: Pfizer, P. Szczypa Shareholder of: Pfizer, Employee of: Pfizer, M. Thakur Shareholder of: Pfizer, Employee of: Pfizer, H. Jones Shareholder of: Pfizer, Employee of: Pfizer, J. Woolcott Shareholder of: Pfizer, Employee of: Pfizer, P. Santos Estrella: None declared, A. Gibofsky Shareholder of: AbbVie, Angen, Celgene, Pfizer, GSK, J and J, Regeneron, Consultant for: AbbVie, Celgene, MSD, Pfizer, Iroko, Horizon, Samumed, Relburn, Sandoz, Speakers bureau: Amgen, AbbVie, Pfizer, Celgene, Iroko, Horizon, MSD, Novartis, C. Rolland Employee of: Envision Pharma Group, G. Citera Consultant for: Pfizer, AbbVie, Bristol Myers Squibb, Novartis, Roche, L. Marshall Shareholder of: Pfizer, Employee of: Pfizer

DOI: 10.1136/annrheumdis-2018-eular.2504

\section{AB0461 EXPERIENCE WITH SUBCUTANEOUS ABATACEPT IN ROUTINE CLINICAL PRACTICE: 6-MONTH INTERIM ANALYSIS OF A 2-YEAR, PROSPECTIVE, NON- INTERVENTIONAL, MULTICENTRE STUDY IN PATIENTS WITH RA}

R. Alten ${ }^{1}$, X. Mariette ${ }^{2}$, M. Buch ${ }^{3}$, R. Caporali ${ }^{4}$, R.-M. Flipo ${ }^{5}$, A. Forster ${ }^{6}$ H. Griffiths ${ }^{7}$, M. Nurmohamed ${ }^{8}$, Y. Patel ${ }^{9}$, P. Peichl ${ }^{10}$, R. Sanmarti ${ }^{11}$, C. Chauvet ${ }^{12}$, J. Heitzman ${ }^{13}$, C. Rauch ${ }^{14}$, S.E. Connolly ${ }^{15} .{ }^{1}$ University Medicine Berlin, Berlin, Germany; ${ }^{2}$ Université Paris-Sud, Paris, France, ${ }^{3}$ University of Leeds, Leeds, UK; ${ }^{4}$ University of Pavia, Pavia, Italy; ${ }^{5}$ Centre Hospitalier Universitaire de France, Lille, France; ${ }^{6}$ Schulthess Klinik, Zürich, Switzerland; ${ }^{7}$ University Hospital Geelong, Geelong, Australia; ${ }^{8} \mathrm{VU}$ University Medical Center and Jan van Breemen Research Institute, Amsterdam, Netherlands; ${ }^{9}$ Hull Royal Infirmary, Hull, UK; ${ }^{10}$ Evangelical Hospital, Vienna, Austria; ${ }^{11}$ Institut d'Investigacions Biomèdiques August Pi i Sunyer, Barcelona, Spain; ${ }^{12}$ DOCS, Nanterre; ${ }^{13}$ Excelya, BoulogneBillancourt, France, ${ }^{14}$ Bristol-Myers Squibb, Munich, Germany; ${ }^{15}$ Bristol-Myers Squibb, Princeton, USA

Background: ASCORE (Abatacept SubCutaneOus in Routine clinical practicE; NCT02090556) is an ongoing, prospective, non-interventional, multicentre study of patients (pts) with RA receiving SC abatacept (ABA). In a similar real-world setting, IV ABA retention was $>88 \%$ at 6 months $(\mathrm{M}){ }^{1}{ }^{1}$

Objectives: To present baseline (BL) pt characteristics and $6 \mathrm{M}$ interim retention rates and clinical outcomes for SC ABA by biologic (b)DMARD treatment line. Methods: Pts ( $\geq 18$ years) with active, moderate-to-severe RA, naïve to $A B A$ and who initiated SC ABA $125 \mathrm{mg}$ weekly were enrolled across 10 countries (March 2013-January 2017) in 2 cohorts: biologic-naïve pts and pts who had failed $\geq 1$ prior bDMARD. In some countries, an IV loading dose was administered according to local practice. Pt demographics and disease characteristics at SC ABA initiation were recorded. The retention rate $(95 \% \mathrm{Cl})$ of SC ABA over $6 \mathrm{M}$ was estimated by Kaplan-Meier analysis. Good/moderate EULAR response rates based on DAS28 (ESR, otherwise CRP), low disease activity (LDA) or remission according to DAS28 (ESR), CDAI, SDAI and Boolean criteria were assessed at $6 \mathrm{M}$.
Results: Of 2943 pts enrolled, 2785 (94.6\%) were evaluable: 1155 (41.5\%) biologic naïve; 718 (25.8\%) had failed 1; and 912 (32.7\%) had failed $\geq 2$ prior biologics. At BL, there was a higher proportion of females and pts with longer disease duration among those who had failed $\geq 2$ vs 1 or no prior bDMARDs; disease activity was similar across treatment lines; CRP was higher in biologic-naïve vs failure pts; 402 (48.4\%) biologic-naïve pts had erosive disease vs $261(53.7 \%)$ or $390(63.8 \%)$ who had received 1 or $\geq 2$ prior bDMARDs, respectively. Probability of overall SC ABA retention at $6 \mathrm{M}$ was $0.88(95 \% \mathrm{Cl} 0.86,0.89)$; retention was higher in pts receiving $A B A$ as a first or second vs later bDMARD (figure 1). At $6 \mathrm{M}$, 335 pts had discontinued ABA, $172(51.3 \%)$ of whom due to inefficacy and 140 $(41.8 \%)$ due to safety. At $6 \mathrm{M}$, among pts continuing ABA, good/moderate EULAR response rates were $83.5 \%, 75.1 \%$ and $72.0 \%$ for biologic-naïve pts and pts with 1 and $\geq 2$ prior bDMARD failures, respectively. DAS28 (ESR), CDAI or SDAI LDA/ remission, or Boolean remission rates were higher with earlier vs later treatment lines. The safety profile was consistent with IV ABA studies. ${ }^{1,2}$

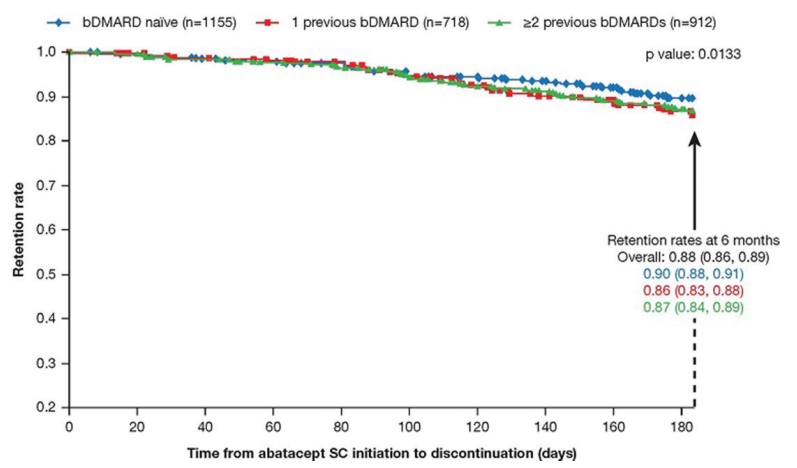

Abstract AB0461 - Figure 1. Abatacept Retention (Time to Discontinuation of SC Abatacept) Over 6 Months by Treatment Line

Conclusions: In this first observation of SC abatacept in a real-world setting, overall retention of $\mathrm{SC}$ abatacept at $6 \mathrm{M}$ was high and similar to that observed with IV abatacept. ${ }^{1}$ Better retention and response rates were achieved with abatacept as an earlier bDMARD treatment line. Good/moderate EULAR response rates at $6 \mathrm{M}$ were consistently $>70 \%$, irrespective of treatment line and higher $\mathrm{BL}$ radiographic erosion in biologic-failure pts.

\section{REFERENCES:}

[1] Nüßlein HG, et al. BMC Musculoskelet Disord 2014;15:14

[2] Nüßlein HG, et al. Clin Exp Rheumatol 2016;34:489-99.

Disclosure of Interest: R. Alten Grant/research support from: Bristol-Myers Squibb, Speakers bureau: Bristol-Myers Squibb, X. Mariette Grant/research support from: Biogen, Pfizer, UCB, Speakers bureau: Bristol-Myers Squibb, LFB GSK, Pfizer, UCB, M. Buch Grant/research support from: AbbVie, AstraZeneca, Eli Lilly, Pfizer, Roche, Sandoz, UCB, Consultant for: AbbVie, AstraZeneca, Eli Lilly, Pfizer, Roche, Sandoz, UCB, R. Caporali Speakers bureau: Bristol-Myers Squibb, AbbVie, Celgene, Eli Lilly, MSD, Pfizer, Roche, UCB, R.-M. Flipo Consultant for: Bristol-Myers Squibb, A. Forster Consultant for: AbbVie, Bristol-Myers Squibb, Pfizer, Celgene, Roche, Novartis, UCB Pharma, Speakers bureau: AbbVie, Bristol-Myers Squibb, Pfizer, Celgene, Roche, Novartis, UCB Pharma, H. Griffiths Grant/research support from: AbbVie, Janssen, and Sanofi, Consultant for: Bristol-Myers Squibb and Janssen, Paid instructor for: Novartis, M. Nurmohamed Grant/research support from: Pfizer, AbbVie, Roche, Bristol-Myers Squibb, MSD, Mundipharma, UCB, Janssen, Menarini, Eli Lilly, Sanofi, Celgene, Consultant for: Pfizer, AbbVie, Roche, Bristol-Myers Squibb, MSD, Mundipharma, UCB, Janssen, Menarini, Eli Lilly, Sanofi, Celgene, Speakers bureau: Pfizer, AbbVie, Roche, Bristol-Myers Squibb, MSD, Mundipharma, UCB, Janssen, Menarini, Eli Lilly, Sanofi, Celgene, Y. Patel Grant/research support from: Bristol-Myers Squibb, Pfizer, AbbVie, Speakers bureau: Bristol-Myers Squibb, Pfizer, AbbVie, P. Peichl Consultant for: Bristol-Myers Squibb, Eli Lilly, R. Sanmarti Grant/ research support from: Bristol-Myers Squibb, Consultant for: Bristol-Myers Squibb, C. Chauvet Employee of: Bristol-Myers Squibb, J. Heitzman Employee of: Bristol-Myers Squibb, C. Rauch Employee of: Bristol-Myers Squibb, S. Connolly Employee of: Bristol-Myers Squibb DOI: 10.1136/annrheumdis-2018-eular.1992 